\title{
PRÁTICAS EXPERIMENTAIS APLICADAS AO ENSINO DE QUÍMICA COMO FERRAMENTA PARA A APRENDIZAGEM
}

\author{
EXPERIMENTAL PRACTICES APPLIED TO TEACHING CHEMISTRY AS A TOOL FOR \\ LEARNING \\ PRÁCTICAS EXPERIMENTALES APLICADAS A LA ENSEÑANZA DE LA QUÍMICA \\ COMO HERRAMIENTA PARA EL APRENDIZAJE
}

Sandra Cadore Peixoto

E-mail: sandracadore@ufn.edu.br

Tiago Barboza Baldez Solner E-mail: tiagosolner@gmail.com

Gabriel de Oliveira Soares E-mail: gsoares8@outlook.com

Leonardo Fantinel

E-mail: leonardofantinel@ufn.edu.br Universidade Franciscana - UFR

RESUMO

Agência: CAPES

Considerando que os recursos didáticos podem ser facilitadores do processo de ensino e aprendizagem, a proposta deste estudo é relatar uma experiência na qual se buscou investigar as opiniões/percepções de estudantes do Ensino Fundamental perante a realização de práticas experimentais direcionadas à aprendizagem de Ciências/Química, além de propor um recurso a essas atividades. Para tal, inicialmente elaborou-se um material de apoio, intitulado "Aprendendo Química", visando favorecer a execução das atividades experimentais conjugadas com as teóricas. Após, as atividades foram aplicadas em uma turma do Ensino Fundamental de uma Escola Pública do município de Paraíso do Sul - RS, constituída por dezessete alunos do 9..$^{\circ}$ ano, buscando incentivar professores à diversidade de atividades na prática docente e despertar interesse científico nos alunos. Após o desenvolvimento das atividades experimentais, solicitou-se aos alunos o preenchimento de um questionário constituído por quatro questões objetivas, com o intuito de avaliar o contexto do aluno perante a Ciência. Frente a isso, a utilização das atividades experimentais descritas neste trabalho contribuiu para o processo de ensino e aprendizagem relacionado à Ciências / Química, pois, permitiu que os alunos se apropriassem dos conhecimentos de forma a poder transformar o seu aprendizado. Os resultados evidenciaram aspectos positivos referentes à realização de práticas experimentais na sala de aula, podendo estas contribuir no aprendizado dos estudantes.

PALAVRAS-CHAVE: Ensino Fundamental. Experimentação em Química. Ensino de Ciências.

\section{ABSTRACT}

Considering that the didactic resources can be facilitators of the teaching and learning process, the purpose of this study is to report an experience in which it was sought to investigate the opinions / perceptions of elementary school students in relation to the realization of experimental practices directed to learning Science/Chemistry, in addition to proposing an appeal to these activities. To this end, a support material, called "Aprendendo Química", was initially developed, aiming to favor the execution of the experimental activities in conjunction with the theoretical ones. Afterwards, the activities were applied in a class of Elementary School of a Public School in the municipality of Paraiso do Sul - RS, constituted by seventeen students of the 9th grade, seeking to encourage teachers to the diversity of activities in the teaching practice and to arouse in students the interest to acquire 
knowledge. After the development of the experimental activities, the students were asked to complete a questionnaire consisting of four objective questions, in order to evaluate the context of the student before Science. Therefore, the use of the experimental activities described in this study contributed to the teaching and learning processes related to Sciences / Chemistry, as it allowed students to appropriate their knowledge in order to transform their learning. The results showed positive aspects for the students' learning, instigating the protagonism of the student. Finally, experimentation played an important role in school learning.

KEYWORDS: Elementary School. Experimentation in Chemistry. Science teaching.

\section{RESUMEN}

Teniendo en cuenta que los recursos didácticos pueden ser facilitadores del proceso de enseñanza y aprendizaje, el propósito de este estudio es informar una experiencia en la que se buscó investigar las opiniones / percepciones de los estudiantes de primaria en relación con la realización de prácticas experimentales dirigidas al aprendizaje de las Ciências/Química, además de proponer un atractivo para estas actividades.Con este fin, inicialmente se desarrolló un material de apoyo, llamado "Aprendendo Química", con el objetivo de favorecer la ejecución de las actividades experimentales en conjunto con las teóricas. Posteriormente, las actividades se aplicaron en una clase de Escuela Primaria de una Escuela Pública en el municipio de Paraíso do Sul - RS, constituida por diecisiete estudiantes de noveno grado, que buscan alentar a los maestros a la diversidad de actividades en la práctica docente y despertar el interés en los estudiantes. para adquirir conocimiento. Después del desarrollo de las actividades experimentales, se pidió a los estudiantes que completaran un cuestionario que constara de cuatro preguntas objetivas, a fin de evaluar el contexto del estudiante antes de la Ciencia. Por lo tanto, el uso de las actividades experimentales descritas en este estudio contribuyó a los procesos de enseñanza y aprendizaje relacionados con las Ciencias / Química, ya que permitió a los estudiantes apropiarse de sus conocimientos para transformar su aprendizaje. Los resultados mostraron aspectos positivos para el aprendizaje de los alumnos, instigando el protagonismo del alumno. Finalmente, la experimentación tuvo un papel importante en el aprendizaje escolar.

PALABRAS-CLAVE: Escuela primária. Experimentación en química. Enseñanza de las ciencias.

\section{INTRODUÇÃO}

A Química é uma ciência que estuda a constituição da matéria e as transformações de uma substância em outra, bem como a energia que está envolvida nessas transformações. Surgiu da curiosidade humana em torno da composição e da identificação de todas as coisas do mundo que nos cerca. Com isso, torna-se importante e indispensável, principalmente nas atividades relacionadas a Ciências.

Estudar Química sem uma orientação didática pode ser uma atividade exaustiva para os alunos, considerando a infinidade de símbolos, teorias, fórmulas e metodologias que são constitutivos desta ciência. Nesta perspectiva, muito alunos entram em um processo de decorar os símbolos e fórmulas, deste modo é de suma importância que o Ensino de Química seja relevante aos estudantes (SAVIANI, 2000). Afinal, esse abrange possibilidades de interdisciplinaridade com diversas áreas do conhecimento, sendo peculiar sua natureza científica.

Geralmente o aluno requer um professor de Ciências e/ou Química que tenha domínio do seu campo de conhecimento. Este conhecimento não é somente o conteúdo que está no livro 
didático, é também o que antecedeu aquele conteúdo e o atual. Para atingir esse objetivo, o professor precisa extrapolar o livro didático, procurando outras fontes que auxiliem o aluno a relacionar os conhecimentos produzidos pelas Ciências. Para isso, o professor tem a necessidade de buscar recursos diferenciados para facilitar a aprendizagem e tornar as aulas de Ciências ou Química mais dinâmicas para os alunos. Esta ciência não pode ser caracterizada por ser meramente teórica.

A utilização de apenas um modelo de ensino tradicional precisa ser repensado nas aulas de Química, tendo em consideração que este é administrado de forma que o aluno saiba inúmeras fórmulas, memorize reações e propriedades, mas sem relacioná-las como fenômeno original que ocorre na natureza.

Trabalhar com as substâncias; aprender a observar um experimento cientificamente; visualizar, de forma que cada aluno descreva o que observou durante a reação: isto sim pode levar a um conhecimento definido. As atividades experimentais permitem ao estudante uma compreensão de como a Ciências/Química se constrói e se desenvolve, afinal foi assim que ela surgiu, também, por meio da Alquimia.

As atividades experimentais, geralmente, comprovam a teoria, além de constituírem-se como uma ótima escolha para diferenciar as aulas ministradas nas escolas. Apesar disso, estas atividades ainda fazem parte de um método didático pouco utilizado - o que se deve, em parte, a vários problemas enfrentados no sistema educacional.

Dessa forma, este estudo tem por objetivo investigar as opiniões/percepções de estudantes do Ensino Fundamental perante a realização de práticas experimentais na aprendizagem da Ciências/Química, além de propor um material de apoio a essas atividades.

Vale ressaltar que esse material (recurso didático) foi elaborado considerando a abordagem de Ciências e de Química relacionadas ao contexto do aluno, trazendo experimentos que contextualizam o conhecimento científico com o cotidiano desses.

Assim, relata-se uma experiência de ensino realizada com uma turma de $9^{\circ}$ ano do Ensino Fundamental de uma Escola Pública do município de Paraíso do Sul - RS, que buscou, além de contribuir com a aprendizagem dos alunos, incentivar os professores à diversidade de atividades na prática docente, no intuito de auxiliar no processo de ensino e aprendizagem.

\section{AS ATIVIDADES EXPERIMENTAIS NO ENSINO DE QUÍMICA}


Os processos de ensino e aprendizagem em Química, nas últimas décadas, buscam promover interfaces, mostrando a Ciência como atividade humana e promovendo saberes necessários à formação social do aluno. Todavia, o processo de ensino e aprendizagem tem se modificado no sentido de oferecer aos alunos possibilidades de visões e diálogos com diversas formas de ver o mundo, valorizando sua vivência, seu contexto social e suas perspectivas futuras, mas ainda são necessárias mudanças de paradigmas frente aos processos de ensino e aprendizagem (SANTOS; SCHNETZLER, 2010, p. 135).

De acordo com Chassot (2003), uma educação mais comprometida envolve a alfabetização científica, ou seja, saber ler a linguagem da natureza. Essa educação compreende a contraposição ao alfabeto científico. A Ciência deve ser vista como algo facilitador do estar fazendo parte do mundo, em uma perspectiva de inclusão social, afinal, "trabalhar com um número excessivo de conceitos, como ocorrem nos currículos tradicionais, tem como pressuposto que aprender química é tão somente aprender o conceito químico" (MALDANER; ZANON, 2007, p. 28).

Segundo Maldaner e Zanon (2007), o modelo de professor tradicional, comprometido mais com o conteúdo do que com o aprender, é o mais presente no sistema escolar, desde a escola básica até a universidade. Partindo deste pressuposto, muitas críticas ao ensino tradicional referem-se ao papel passivo atribuído ao aluno, que frequentemente é tratado como mero ouvinte das informações que o professor expõe. Tais informações, quase sempre, não se relacionam aos conhecimentos prévios que os estudantes construíram ao longo de sua vida. $\mathrm{E}$ quando não há relação entre o que o aluno já sabe e aquilo que ele está aprendendo, a aprendizagem é pouco significativa.

No Ensino de Ciências, a experimentação pode ser uma estratégia eficiente para a criação de problemas reais que permitam a contextualização e o estímulo de questionamentos de investigação. A atividade experimental geralmente serve para comprovar a teoria científica. Pode-se utilizar o mesmo experimento para o estudo de um determinado conteúdo. Isso acaba facilitando o trabalho do professor, pois no planejamento das aulas ele já tem uma noção do que utilizar para cada conteúdo específico. A escolha de uma aula prática para determinado conteúdo não é fácil, pois ao fazer a opção, o professor necessita de tempo para realizar a pesquisa e o planejamento. Deve-se levar em conta a escolha pelo experimento mais simples, com materiais de fácil acesso e que não exijam muita prática de manuseio, para que o aluno possa entender e associar com a teoria. A escolha de reagentes a serem utilizados também 
influencia, pois estes não devem requerer muita sofisticação para a sua utilização (FONSECA, 2001).

Além de todas essas questões, destaca-se ainda que o experimento precisa instigar a atenção dos alunos, provocando a motivação e a curiosidade destes para participar das aulas, e assim entender como o experimento funciona, o que acontece naquele momento: o que causa a mudança de cor, a formação de um precipitado, a liberação de um gás, a diminuição da temperatura, entre outros. O que prende muita a atenção do aluno é o visual, ou seja, precisam ser experimentos com grande apelo visual, com mudança de cor ou forma, que seja algo claramente diferente (FEITOSA, 2011).

Guimarães (2009) afirma que as aulas práticas podem ser assumidas como uma excelente estratégia para a criação de problemas contextualizados e, assim, responder aos questionamentos dos estudantes durante a interação com essa atividade. Assim, entende-se que a experimentação pode ser uma eficiente estratégia no Ensino de Ciências, que permite a contextualização dos conhecimentos. É necessário que se leve em consideração que a observação no Ensino de Ciências não é feita em um vazio conceitual, mas a partir de um corpo teórico que a orienta (GUIMARÃES, 2009).

É de conhecimento dos professores de Ciências o fato de a experimentação despertar um forte interesse entre os alunos em diversos níveis de escolarização. Em seus depoimentos, os alunos também costumam atribuir à experimentação um caráter motivador, lúdico, essencialmente vinculado aos sentidos. Por outro lado, não é incomum ouvir de professores a afirmativa de que a experimentação aumenta a capacidade de aprendizado, pois funciona como meio de envolver o aluno nos temas que estão em pauta.

Com isso, este estudo justifica-se pela necessidade de incentivar os professores a relacionar teoria com prática, otimizando as metodologias experimentais relacionadas a Ciências/Química utilizadas no Ensino Fundamental, viabilizando assim uma melhor relação entre o ensino e a adequada aprendizagem dos alunos.

\section{CAMINHOS METODOLÓGICOS}

Após uma reflexão sobre a importância das atividades experimentais no Ensino Fundamental, percebeu-se a necessidade da realização de uma revisão teórica aprofundada referente às práticas experimentais, possíveis de serem aplicadas no contexto escolar de uma Escola Pública de Ensino Fundamental do município de Paraíso do Sul - RS. 


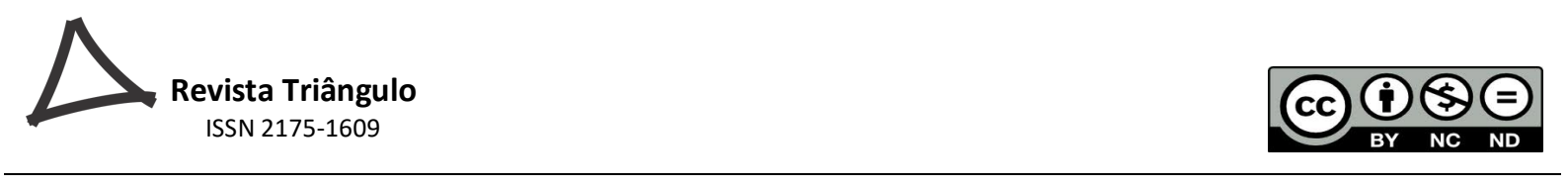

A escola dispunha de um laboratório de Ciências desativado, que necessitaria de um processo de revitalização a fim de ser utilizado como um espaço para aprendizagem. Desse modo, pensou-se na elaboração de um recurso didático, na forma de material de apoio, contendo a descrição de experimentos possíveis de serem realizados em sala de aula, intitulado "Aprendendo Química", que visou favorecer a execução das atividades experimentais conjugadas com as teóricas, para assim contribuir para a melhoria do entendimento e da aprendizagem dos conteúdos propostos pela área.

Vale destacar que este material foi elaborado com base em experimentos relacionados à Ciência, de simples execução e com materiais de fácil aquisição, possibilitando assim a utilização por grande parte dos professores interessados. Todos os experimentos foram previamente testados na Universidade Franciscana.

Assim, após a elaboração do recurso didático, foi realizado um encontro na escola a fim de apresentá-lo à equipe diretiva e aos professores de Ciências/Química, buscando viabilizar a aplicação dos experimentos no contexto da escola.

Em seguida, as atividades experimentais foram aplicadas em uma turma do $9^{\circ}$ ano do Ensino Fundamental da escola, constituída por dezessete alunos.

Posteriormente a aplicação das práticas, foi solicitado aos alunos que respondessem um questionário que continha questões referentes as suas percepções quanto à realização dos experimentos para a sua própria aprendizagem.

\section{RESULTADOS E DISCUSSÕES}

\section{O material de apoio}

Considerando que a atividade experimental deve apresentar condições para que os alunos possam levantar e testar suas ideias e teorias sobre o que aprenderam em sala e o que ocorre em sua volta, o material de apoio foi pensado para servir de orientação para o planejamento das atividades experimentais a serem executadas, a fim de instigar e fortalecer a inteligência dos alunos.

O material foi elaborado, inicialmente, por dois mestrandos na área de Ensino de Ciências e Matemática e uma professora orientadora do Programa de Pós-graduação do qual os alunos fazem parte. 
O recurso didático apresenta-se no modelo de uma cartilha, constituído pela descrição de cinco experimentos possíveis de serem aplicados com alunos do Ensino Fundamental na própria sala de aula dos estudantes. A Figura 1 ilustra a capa do material de apoio produzido, remetendo aos títulos dos experimentos. 
Figura 1 - Capa do material de apoio.

PROGRAMA DE PÓS GRADUAÇÃo EM ENSINO DE CIÊNCIAS E MATEMÁTICA

APRENDENDO QUÍMICA

\section{Experimentos: $9^{\circ}$ ano do Ensino Fundamental}

Experimento 1: Densidade dos materiais

Experimento 2: Tratamento da água

Experimento 3: Escrever mensagem secreta

Experimento 4: 0 enchimento automático de balões

Experimento 5: Rompendo a tensão superficial

Fonte: Autoria própria.

O Quadro 1 descreve os títulos, os materiais a serem utilizados e os procedimentos dos cinco experimentos que compõem a cartilha.

Quadro 1 - Título, materiais utilizados e procedimento dos cinco experimentos realizados.

\begin{tabular}{|c|c|c|}
\hline Título & Materiais utilizados & Procedimento \\
\hline $\begin{array}{l}\text { Densidade dos } \\
\text { materiais }\end{array}$ & $\begin{array}{l}\text { Água; } \\
\text { Óleo; } \\
\text { Um pouco de serragem; } \\
\text { Um pedaço de madeira; } \\
\text { Uma tampa de latinha; } \\
\text { Proveta graduada ou um copo de } \\
\text { vidro. }\end{array}$ & $\begin{array}{l}\text { Em uma proveta graduada ou copo de vidro, } \\
\text { adicione a tampa da latinha, água, um pedaço de } \\
\text { madeira, gasolina e um pouco de serragem. Adicione } \\
\text { estes materiais nesta ordem e observe a diferença de } \\
\text { densidade. }\end{array}$ \\
\hline $\begin{array}{c}\text { Tratamento da } \\
\text { água }\end{array}$ & $\begin{array}{l}\text { Frascos de vidro (como os de } \\
\text { maionese ou café solúvel); } \\
\text { Colher de plástico de sobremesa; } \\
\text { Sulfato de alumínio p.a. }\left(\mathrm{Al}_{2}\left(\mathrm{SO}_{4}\right)_{3}\right) ; \\
\text { Hidróxido de sódio p.a. (soda } \\
\text { cáustica } \mathrm{NaOH}) ; \\
\text { Solo (terra); } \\
\text { Filtro de areia e carvão preparado } \\
\text { com garrafa pet. }\end{array}$ & $\begin{array}{l}\text { Coloque água da torneira até cerca de } 2 / 3 \text { do volume } \\
\text { do vidro; } \\
\text { Adicione uma "pitada" de terra (só para a água ficar } \\
\text { turva); } \\
\text { Adicione uma colher rasa de soda cáustica }(\mathrm{NaOH}) \\
\text { e agite a solução cuidadosamente com a colher. } \\
\text { Lave a colher tomando cuidado para não colocar os } \\
\text { dedos na parte que tocou na solução de soda cáustica } \\
\text { e enxugue com um pedaço de papel; } \\
\text { Em seguida, com a colher seca, adicione } 2 \text { colheres } \\
\text { rasas de sulfato de alumínio e misture muito bem; } \\
\text { Deixe em repouso em torno de } 10 \text { minutos. Anote } \\
\text { suas observações; } \\
\text { Filtre o sobrenadante e recolha o filtrado. Para } \\
\text { preparar o filtro, corte a garrafa ao meio e inverta a } \\
\text { parte superior, encaixando-a na base. Enrole um } \\
\text { tecido na boca da garrafa e preencha com carvão e } \\
\text { areia. } \\
\text { No final do experimento: } \\
\text { Deposite o precipitado presente no vidro (Al(OH) } 3 \text { ) } \\
\text { em um recipiente fornecido pelo professor. A } \\
\text { legislação brasileira permite que a água tratada } \\
\text { tenha no máximo 0,1 mg/L de alumínio. O } \\
\text { hidróxido de alumínio produzido no experimento } \\
\text { poderá ser recuperado ou a solução poderá ser } \\
\text { diluída com água da torneira até que se atinjam } \\
\text { níveis aceitáveis pela legislação. Só então esta } \\
\text { poderá ser descartada na pia. Lave todo material e } \\
\text { organize sua bancada. }\end{array}$ \\
\hline
\end{tabular}


Quadro 1 - Título, materiais utilizados e procedimento dos cinco experimentos realizados

(conclusão)

\begin{tabular}{|c|c|c|}
\hline $\begin{array}{l}\text { O enchimento } \\
\text { automático de } \\
\text { balões }\end{array}$ & $\begin{array}{l}\text { Garrafa de gargalo estreito ou } \\
\text { erlenmeyer; } \\
\text { Funil de plástico ou de vidro; } \\
\text { Balão (bexiga); } \\
\text { Vinagre; } \\
\text { Bicarbonato de sódio. }\end{array}$ & $\begin{array}{l}\text { Colocar vinagre para dentro de uma garrafa de } \\
\text { gargalo estreito até encher cerca de um quarto da } \\
\text { mesma; } \\
\text { Com o funil, colocar no balão um pouco de } \\
\text { bicarbonato de sódio; } \\
\text { Colocar o gargalo do balão no gargalo da garrafa. } \\
\text { Levantar o balão de modo a que o bicarbonato de } \\
\text { sódio caia para dentro da garrafa; } \\
\text { O vinagre começa a fazer bolhas e o balão começa } \\
\text { a encher devagarinho }\end{array}$ \\
\hline $\begin{array}{c}\text { Rompendo a } \\
\text { tensão superficial }\end{array}$ & $\begin{array}{l}1 \text { prato fundo contendo água ou } \\
\text { leite; } \\
\text { Um pouco de talco ou corante } \\
\text { alimentício ou pedacinhos de papel } \\
\text { ofício; } \\
\text { Detergente de cozinha; } \\
\text { Palitos de dente ou cotonetes. }\end{array}$ & $\begin{array}{l}\text { Coloque um pouco de água ou leite em um prato } \\
\text { fundo e espere até que fique bem parada no prato; } \\
\text { Jogue um pouco de talco na superfície da água e } \\
\text { observe. Você pode ver que o talco não afunda na } \\
\text { água; } \\
\text { Molhe a ponta de um palito de dente ou cotonete } \\
\text { com detergente de cozinha; } \\
\text { Com cuidado, encoste a ponta do palito com } \\
\text { detergente no centro do prato onde está o talco e } \\
\text { observe com bastante cuidado. O que aconteceu com } \\
\text { o talco? } \\
\text { Faça a mesma experiência usando corante de } \\
\text { alimento. O corante deve ser colocado com bastante } \\
\text { cuidado na superfície da água. Agora, você vai } \\
\text { colocar o detergente na lateral do prato e não no } \\
\text { meio! Coloque uma gota de detergente na lateral do } \\
\text { prato e deixe escorrer até a água. É bem legal ver o } \\
\text { que acontece com o corante quando o detergente } \\
\text { encontra a água! }\end{array}$ \\
\hline $\begin{array}{c}\text { Escrever } \\
\text { mensagem secreta }\end{array}$ & $\begin{array}{l}\text { Copo de vidro ou plástico; } \\
\text { Pincel fino; } \\
\text { Folha de papel; } \\
\text { Faca; } \\
\text { Suco de limão. }\end{array}$ & $\begin{array}{l}\text { Corte um limão ao meio, com a ajuda de uma faca; } \\
\text { Esprema o suco do limão para o interior do copo; } \\
\text { Com a ajuda do pincel, escreve uma mensagem com } \\
\text { a solução de limão, numa folha de papel branca; } \\
\text { Coloque o papel em um local seco, deixando que a } \\
\text { tua mensagem se torne realmente invisível. } \\
\text { Para revelar a tua mensagem, fazer o seguinte: } \\
\text { Com a mensagem virada para baixo, passar a ferro, } \\
\text { utilizando um ferro quente (deve fazê-lo sobre a } \\
\text { tábua de passar, colocando um pano velho por baixo, } \\
\text { para não sujar); } \\
\text { Repetir várias vezes, desligar o ferro e virar a } \\
\text { mensagem ao contrário; } \\
\text { A mensagem aparece em cor castanha, bem visível. }\end{array}$ \\
\hline
\end{tabular}

Fonte: autoria própria.

Após a elaboração do material, foi realizada uma visita à escola na qual se aplicariam as atividades, a fim de apresentar o recurso didático produzido aos professores de Ciências. Assim, nessa primeira visita, foi identificado que eles demonstravam interesse e disponibilidade em promover uma prática experimental com seus alunos, mostrando-se bastante receptivos à proposta. 


\section{Aplicação das atividades}

Para iniciar as atividades foi entregue a cada aluno uma cópia do material de apoio. A seguir, os alunos foram organizados em um semicírculo dentro da sala de aula, para que assim realizassem as atividades de experimentação propostas.

Vale destacar que todos os reagentes utilizados foram de fácil acesso e as reações químicas não envolveram grau de toxicidade, portanto, os experimentos foram realizados na própria sala de aula dos alunos.

Todos os experimentos foram realizados em um grande grupo, para que os alunos, em contato com os colegas, pudessem discutir e trocar opiniões sobre os conceitos que estavam envolvidos na prática realizada, destacando-se momentos em que se mostraram surpresos com os resultados de algumas reações, demonstrando interesse em compreender a fundamentação científica que baseava o processo realizado.

Assim, todas as reações químicas que emergiram dos experimentos foram explicadas aos alunos, incentivando-os a estudar os conceitos científicos envolvidos nas práticas experimentais.

\section{O questionário}

Após o desenvolvimento das atividades experimentais, solicitou-se aos alunos o preenchimento de um questionário constituído por quatro questões objetivas, com o intuito de avaliar o contexto do aluno perante a Ciência.

1. Você já tinha realizado alguma prática experimental relacionada ao Ensino de Ciência?

2. Através da atividade proporcionada no dia de hoje, você consegue relacionar com algo já estudado na escola, referente à Ciência?

3. A partir dos experimentos de hoje, você consegue relacionar a Ciência com o seu cotidiano?

4. O que você achou de realizar atividades práticas no mesmo ambiente da sala de aula?

Para as questões de números 1, 2 e 3, as opções de respostas foram "Sim" ou "Não". Na questão de número 4, as opções foram: "boa ideia", "ótimo", "razoável” e "não gostei".

A Figura 2 apresenta um gráfico que sistematiza as respostas dos estudantes às questões de números 1, 2 e 3 do questionário aplicado posteriormente a realização dos experimentos. 
Figura 2 - Gráfico de sistematização das respostas dos alunos às questões 1, 2 e 3.

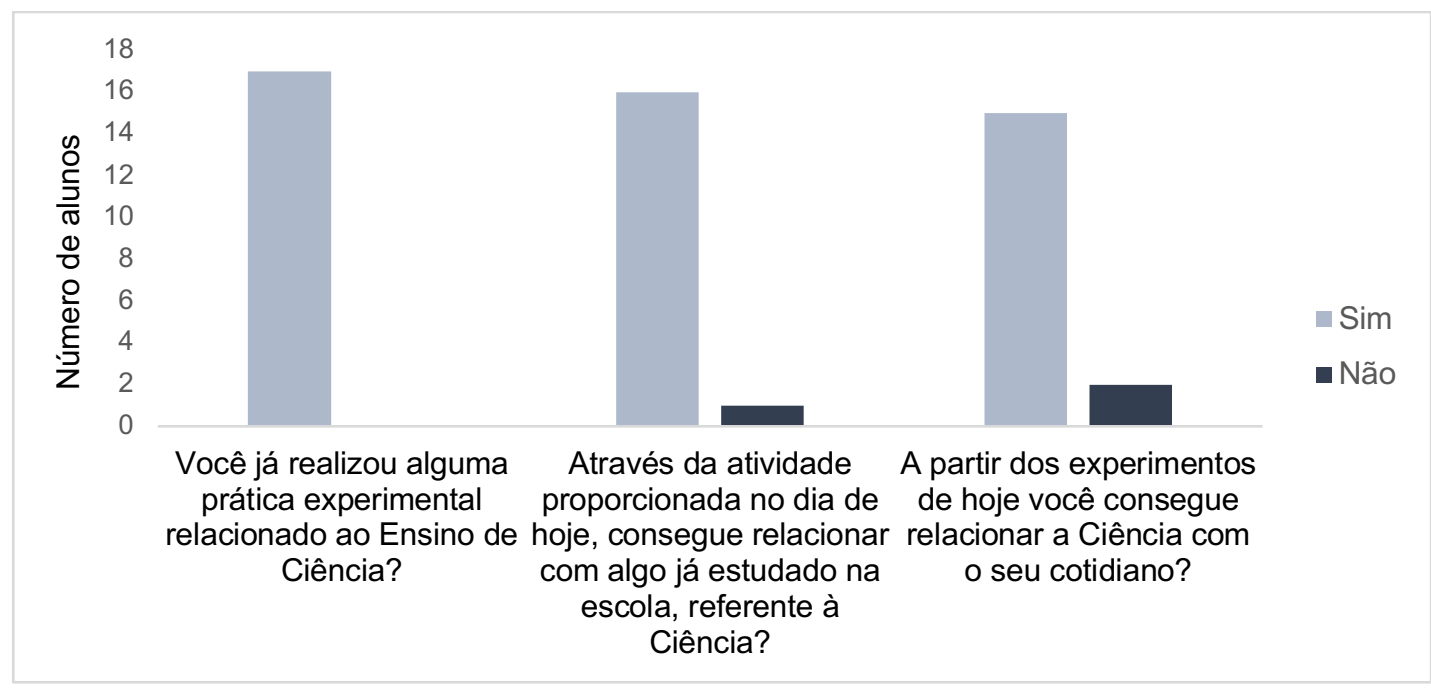

Fonte: dados da pesquisa.

De acordo com a Figura 2, todos os alunos responderam que já tinham realizado alguma prática experimental relacionada ao Ensino de Ciências. Apenas um aluno afirmou que não conseguiu relacionar a atividade realizada com algo já estudado na escola referente à Ciência. Dois alunos relataram que não conseguem associar a atividade realizada com o seu cotidiano.

A Figura 3 apresenta o gráfico que destaca as respostas dos alunos referentes à questão de número 4.

Figura 3 - Gráfico de sistematização das respostas dos alunos à questão 4.

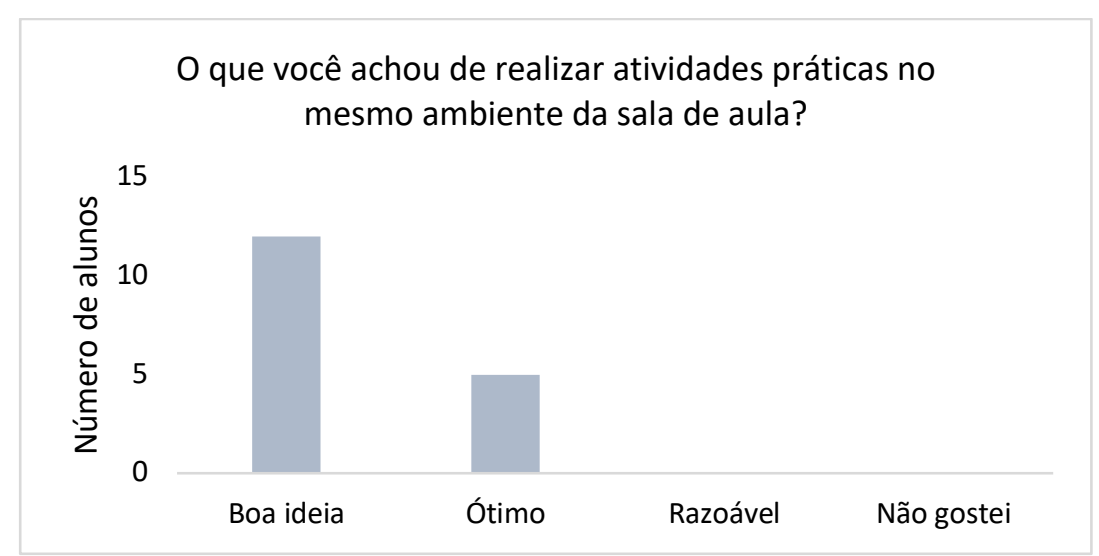

Fonte: dados da pesquisa. 


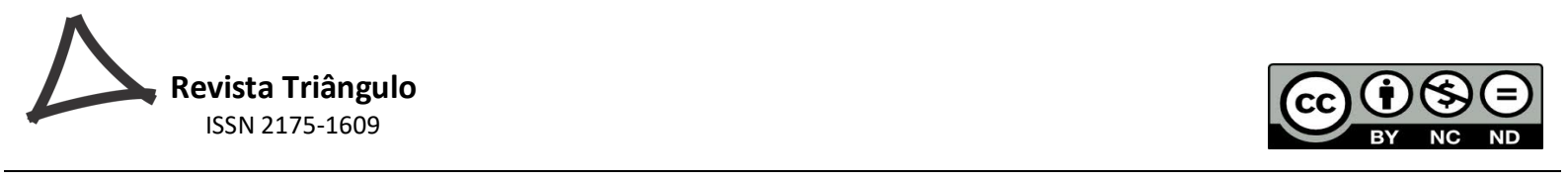

Conforme a Figura 3, doze alunos afirmaram que foi uma boa ideia realizar atividades práticas no mesmo ambiente da sala de aula, sendo que cinco alunos consideraram uma ótima opção.

Isso corrobora as ideias apresentadas anteriormente, que a utilização de experimentos nas aulas de Ciências/Química proporciona aos estudantes um maior interesse pela Ciência, além de dinamizar o ambiente de aprendizagem, favorecendo a construção de um conhecimento com significado para eles.

\section{CONSIDERAÇÕES FINAIS}

Levando em consideração a disponibilidade de tempo que o professor tem para o planejamento de atividades para o desenvolvimento do conteúdo programático, e frente ao fato de muitos não terem um laboratório de Ciências equipado à sua disposição na Escola, fica evidenciado um grande obstáculo no que diz respeito ao ensino prático conjugado ao teórico. Desta forma, a experimentação executada de forma simples, porém com fundamentação científica, pode contribuir de modo muito positivo no processo de ensino e aprendizagem dos alunos.

Com isso, este trabalho apresentou o relato de uma experiência de ensino, na qual buscou-se investigar as opiniões/percepções de estudantes do Ensino Fundamental perante a realização de práticas experimentais na aprendizagem da Ciências/Química, além de propor um material de apoio a essas atividades.

Nesse estudo, a execução de atividades experimentais em sala de aula demonstrou ser uma metodologia viável como ferramenta de ensino. Além de proporcionar a valorização dos aspectos sociais e sua relação com os conteúdos programáticos, as atividades experimentais contribuíram de forma positiva no aprendizado de cada aluno.

Considerando que a experimentação foi desenvolvida em um grande grupo, os alunos puderam desenvolver a aprendizagem colaborativa, enfatizando a importância de se trabalhar em grupo. A contextualização das atividades possibilitou a correlação entre Ciência e o cotidiano de cada aluno. Com isso, abriu-se espaço para a discussão das questões que envolvem a relação entre ciência, tecnologia e sociedade no mundo, colaborando para a formação de um aluno mais crítico. 
É relevante destacarmos que através da experimentação no ensino de Ciências/Química, especialmente na educação básica, é possível verificar por via da quantificação dos resultados, o nível altamente expressivo de aceitação da experimentação.

Conclui-se, então, que o ensino e a aprendizagem podem ser fortalecidos por meio de atividades experimentais, pois essas são capazes de promover um papel mais ativo e investigativo do aluno em sala de aula; além de o engajamento entre professores e alunos, referente ao estudo da Ciências/Química receber mais evidência, contribuindo para o aprendizado do aluno e favorecendo as práticas didáticas do professor na contextualização e na qualificação do ensinamento teórico associado aos experimentos utilizados.

Portanto, acredita-se que a utilização das atividades experimentais descritas neste trabalho pode contribuir para o processo de ensino e de aprendizagem relacionado a Ciências/Química, pois permite que os alunos se apropriem dos conhecimentos de forma a poder transformar o seu aprendizado.

\section{AGRADECIMENTOS}

O presente trabalho foi realizado com apoio da Coordenação de Aperfeiçoamento de Pessoal de Nível Superior - Brasil (CAPES) - Código de Financiamento 001.

\section{REFERÊNCIAS}

CHASSOT, A. Alfabetização científica: uma possibilidade para a inclusão social. Revista Brasileira de Educação, n. 22, p. 89-100, jan./abr. 2003.

FEITOSA, R. A.; LEITE, R. C. M.; FREITAS, A. L. P. Projeto Aprendiz: interação universidade-escola para realização de atividades experimentais no ensino médio. Ciência \& Educação [on-line], Bauru, v. 17, n. 2, p.301-320, 2011.

FONSECA, M. R. M. Completamente química: química geral. São Paulo: FTD, 2001.

GUIMARES, C. C. Experimentação no Ensino de Química: Caminhos e descaminhos rumo à aprendizagem significativa. Química Nova na Escola, v. 31, n. 3, p. 198-202, 2009.

MALDANER, O. A.; ZANON, L. B. Fundamentos e Propostas de Ensino de Química para a Educação Básica no Brasil. Ijuí: UNIJUÍ, 2007.

SANTOS, W. L. P.; SCHNETZLER, R. P. Educação em Química: compromisso com a cidadania. 4. ed. Ijuí: UNIJUÍ, 2010. 
SAVIANI, O. Pedagogia histórico-crítica: primeiras aproximações. 7. ed. Campinas, SP: Autores Associados, 2000. 